\title{
Loss of Drosophila Coq8 results in impaired survival, locomotor deficits and photoreceptor degeneration
}

\author{
Angelia J. Hura' ${ }^{1}$, Hannah R. Hawley ${ }^{1}$, Wei Jun Tan ${ }^{1}$, Rebecca J. Penny' ${ }^{1}$, Jessie C. Jacobsen² and \\ Helen L. Fitzsimons ${ }^{1 *}$ (])
}

\begin{abstract}
Coenzyme Q8A encodes the homologue of yeast c098, an ATPase that is required for the biosynthesis of Coenzyme Q10, an essential component of the electron transport chain. Mutations in COQ8A in humans result in CoQ10 deficiency, the clinical features of which include early-onset cerebellar ataxia, seizures and intellectual disability. The rapid advancement of massively parallel sequencing has resulted in the identification of more than 40 new mutations in COQ8A and functional studies are required to confirm causality and to further research into determining the specific mechanisms through which the mutations result in loss of function. To that end, a Drosophila model of Coq8 deficiency was developed and characterized to determine its appropriateness as a model system to further explore the role of Coq8 in the brain, and for functional characterisation of Coq8 mutations. Pan-neuronal RNAi knockdown of Coq8 was largely lethal, with female escapers displaying severe locomotor deficits. Knockdown of Coq8 in the eye resulted in degeneration of photoreceptors, progressive necrosis and increased generation of reactive oxygen species. Reintroduction of wild-type Coq8 restored normal function, however expression of human wild-type COQ8A exacerbated the eye phenotype, suggesting it was acting as a dominant-negative. This model is therefore informative for investigating the function of Drosophila Coq8, however human COQ8A mutations cannot be assessed as hCOQ8A does not rescue Coq8 deficiency.
\end{abstract}

Keywords: coq8, COQ8A, Coenzyme Q10, Brain, Neuron, Drosophila, Neurodevelopment, Neurodegeneration, Photoreceptor, Mitochondria

\section{Main text}

Coenzyme Q10 (CoQ10, ubiquinone) is an essential component of the electron transport chain that shuffles electrons from complex I and complex II to complex III for mitochondrial respiration. Biosynthesis of CoQ10 in humans is orchestrated by a number of enzymes that are highly conserved across the animal kingdom [1]. One such enzyme is Coenzyme Q8A ( $A D C K 3, C A B C 1)$,

*Correspondence: h.l.fitzsimons@massey.ac.nz

${ }^{1}$ School of Natural Sciences, Massey University, Palmerston North, New Zealand

Full list of author information is available at the end of the article an atypical kinase of the UbiB protein kinase-like family, which localizes to the inner mitochondrial matrix [2] where it is activated by lipid precursors [3]. Its specific role in CoQ10 biosynthesis has not been fully elucidated, however it exhibits ATPase activity and is thought to couple hydrolysis of ATP to extraction of lipids into the aqueous matrix [3]. COQ8A also associates with other COQ biosynthetic proteins (COQ3-9), forming Complex $\mathrm{Q}[2,4]$, and the presence of COQ8A is integral to its stability, as knockout of COQ8A in the mouse reduces the expression of all other COQ proteins in the complex in multiple tissues including the cerebellum and skeletal muscle [4]. original author(s) and the source, provide a link to the Creative Commons licence, and indicate if changes were made. The images or other third party material in this article are included in the article's Creative Commons licence, unless indicated otherwise in a credit line to the material. If material is not included in the article's Creative Commons licence and your intended use is not permitted by statutory regulation or exceeds the permitted use, you will need to obtain permission directly from the copyright holder. To view a copy of this licence, visit http://creativecommons.org/licenses/by/4.0/. The Creative Commons Public Domain Dedication waiver (http://creativeco mmons.org/publicdomain/zero/1.0/) applies to the data made available in this article, unless otherwise stated in a credit line to the data. 
Mutations in COQ8A in humans result in CoQ10 deficiency (OMIM: 612,016), the clinical features of which include early-onset cerebellar ataxia, seizures and intellectual disability [5-8]. The rapid advancement of massively parallel sequencing methodologies has resulted in the identification of more than 40 mutations in COQ8A [6-15] [16-22] and functional studies are required to confirm causality and to determine the specific mechanisms through which the mutations impact function. To that end, we developed and characterized a Drosophila model of Coq8 deficiency to further explore the role of Coq8 in the brain, and to assess the impact of loss of function $\operatorname{Coq} 8$ mutations. Drosophila $\operatorname{Coq} 8$ (CG32649) is orthologous to human COQ8A, sharing $53 \%$ identity $/ 70 \%$ similarity in the C-terminal two-thirds of the protein (NCBI BLAST, accession NP_572836.1 vs NP_064632.2), which contains conserved sequence motifs that are central to the function of human COQ8A $[3,4][23]$.

We first investigated the importance of Coq8 to neuronal function in Drosophila via RNAi knockdown with the UAS/GAL4 system [24]. Pan-neuronal knockdown was lethal when flies were raised at $25^{\circ} \mathrm{C}$, however, when raised at $18{ }^{\circ} \mathrm{C}$ (at which temperature GAL4 is less active and thus there is reduced RNAi) some female flies survived (Fig. 1A), allowing characterization of the impact of Coq8 depletion on neuronal phenotypes. The female survivors displayed reduced movement with a tendency to accumulate at the bottom of the vial, therefore their locomotor function was assessed with the negative geotaxis assay [25]. Female flies displayed a profound climbing deficit, with only $3 \%$ climbing over $5 \mathrm{~cm}$ in comparison to $70 \%$ of controls which express GAL4 but do not carry the RNAi construct (Fig. 1B).

We next sought to examine whether the behavioral changes were associated with changes in brain morphology and function. The gross architecture of the brain was assessed via immunohistochemistry with antiBruchpilot, which labels the synaptic neuropil and allows visualization of the ultrastructure of the brain [26]. No gross morphological deficits were observed (Fig. 1C) and examination of individual sections did not indicate increased vacuolation.

We next examined the impact of Coq8 depletion on photoreceptor development and integrity and observed a profound impairment in ommatidial patterning, with detachment of ommatidia and misaligned bristles (Fig. 1D). Each ommatidium develops with a characteristic asymmetric trapezoid arrangement of photoreceptors as visualized by Nile Red, which stains lipids in the rhabdomeres [27] (Fig. 1E top). When Coq8 was reduced, this regular arrangement was disrupted
(Fig. 1E bottom). As COQ8A mutations have been associated with oxidative stress [2], dihydroethidium staining [28] was performed on retina, which showed an increase in reactive oxygen species (Fig. 1F). Necrotic patches were also evident on the surface of the eye (Fig. 1G) and a progressive increase in necrosis was observed, with area of the necrotic tissue increasing in size 111-fold in males and 490-fold in females from day 3 to 42 (Fig. $1 \mathrm{H}, \mathrm{p}<0.0001$ ).

Expression of Myc-tagged wild-type Coq8 in neurons resulted in robust expression in the adult brain and appropriate localization to mitochondria as indicated by colocalization with mito-GFP [29] (Fig. 1I). Coexpression of Coq 8 rescued the male lethality resulting from $\operatorname{Coq} 8$ knockdown (Fig. 1J), as well as the climbing deficits (Fig. 1K) and necrosis (Fig. 1L, M), confirming the specificity of the RNAi. Two mutants of Coq8 (I295P and L520*) were generated that were based on corresponding human mutations (p.Leu277Pro and c. $1506+1 \mathrm{G}>\mathrm{A}$ ) that we previously identified in a sibling pair [7]. Unlike the complementation observed on reintroduction of WT Coq8, neither mutant rescued the lethality (Fig. 1J), the climbing deficits (Fig. 1K) or impaired eye development (Fig. 1M). Immunohistochemical analyses revealed that expression of I295P was reduced and L520* expression was not detected (Additional file 3). We next examined whether human wild-type COQ8A could rescue Coq8 knockdown. The $h C O Q 8 A$ cDNA was expressed and localized appropriately to mitochondria (Fig. $1 \mathrm{~N})$. However, it was unable to rescue male lethality (Fig. 1O), climbing deficits (Fig. 1P) or necrosis (Fig. 1Q, R), in fact expression of hCOQ8A in a wild-type background impaired survival and climbing. Moreover, hCOQ8A also appeared to act as a dominant-negative in the eye, resulting in a more severe phenotype than Coq 8 knockdown alone, with smaller eyes displaying a complete loss of ommatidial integrity and pigmentation, resulting in a glossy phenotype (Fig. 1Q), which has been previously observed in mutants for mitochondrial function [30]. Coq8 functions as a dimer, thus it is possible that hCOQ8A interferes with Coq8 function, the impact of which is exacerbated when Coq8 is already depleted.

Taken together, these data show that Coq8 is essential for survival in Drosophila, and is required for normal locomotor function and survival of photoreceptors. This model of Coq 8 deficiency can be used for investigating the function of Drosophila Coq8. The lack of rescue by hCOQ8A suggests that Drosophila Coq 8 has additional functions to hCOQ8A and warrants further investigation. 


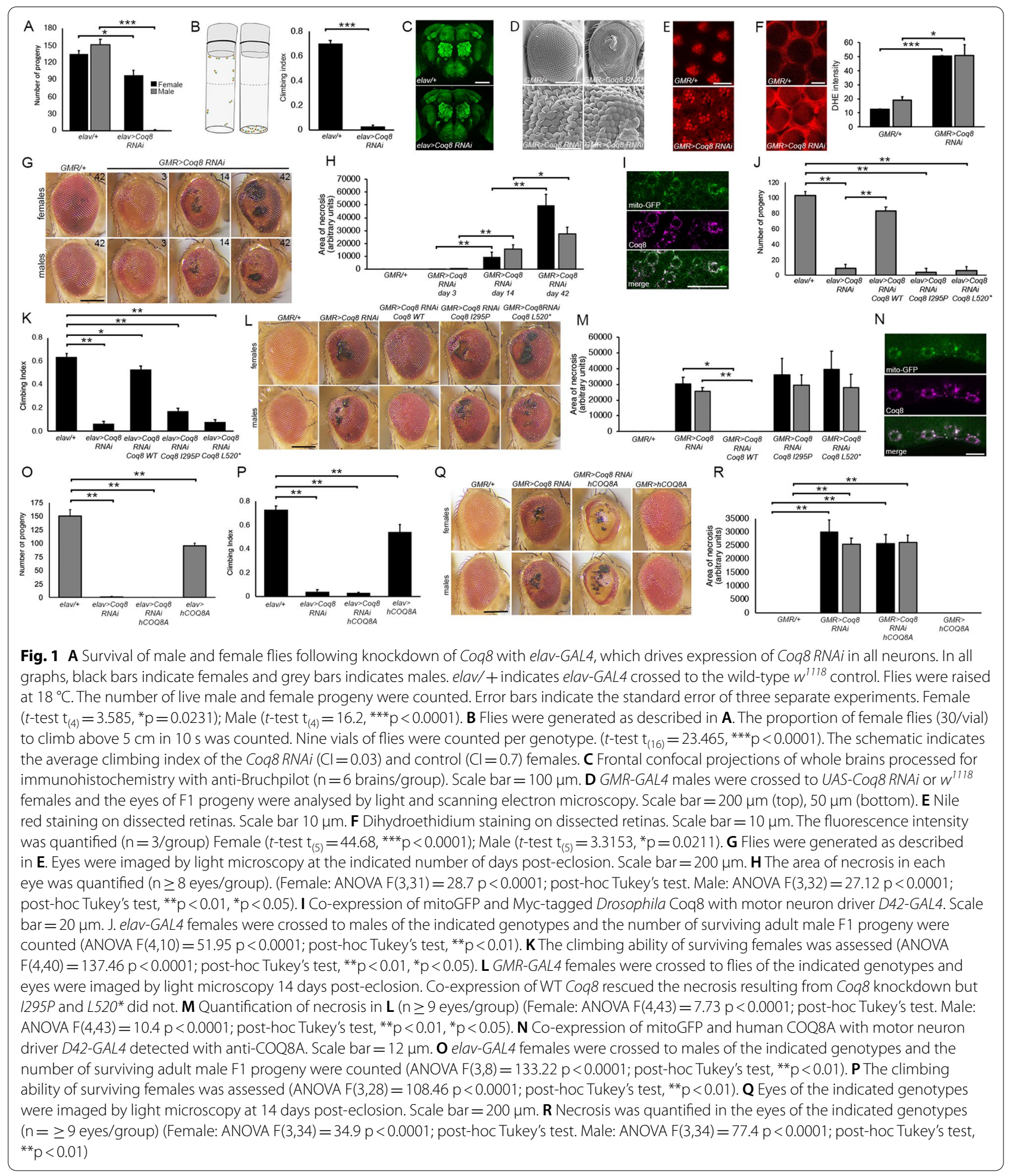

\section{Supplementary Information}

The online version contains supplementary material available at https://doi. org/10.1186/s13041-022-00900-3.
Additional file 1. Materials and Methods.

Additional file 2. References 16 to 30 .

Additional file 3: Figure S1. Expression of Myc-tagged WT Coq8, Cog8 1295P and Cog8 L520* in the Drosophila brain. Anti-Myc (green) detects 
the Myc-tagged proteins, and anti-Bruchpilot detects the neuropil marker nc82 (magenta). All genotypes were generated by crossing elav-GAL4 females to males carrying each indicated UAS-Cog8 transgene and to the $w^{1118}$ control (elav-GAL4/+). Representative images of frontal confocal projections of whole brains ( $n=6 /$ group) are shown. Robust expression of WT Cog8 was observed across the brain, with localization to the cytoplasm of neurons as seen in the magnified image in the inset. Expression of $1295 \mathrm{P}$ was much reduced, and L520* was not detected, with staining at a similar level to the control. Scale bar $=100 \mu \mathrm{m}$.

\section{Acknowledgements}

We thank the Manawatu Microscopy and Imaging Centre for scanning electron and confocal microscopy and Ana Claasen for technical assistance.

\section{Authors' contributions}

HLF conceived the study and designed the experiments. AJH, HRH, HLF, WJT and RJP generated experimental data. JCJ co-designed the mutant analysis. $H L F, A J H$ and $H R H$ wrote the manuscript and all authors read and approved the final manuscript.

\section{Funding}

This work was supported by a grant from the Palmerston North Medical Research Foundation to HLF. The funding bodies had no role in the design of the study and collection, analysis, interpretation of data, or in writing the manuscript.

\section{Availability of data and materials}

The datasets supporting the conclusions of this article are included within the article.

\section{Declarations}

\section{Ethics approval and consent to participate}

Not applicable.

\section{Consent for publication}

Not applicable.

\section{Competing interests}

The authors declare they have no competing interests.

\section{Author details}

${ }^{1}$ School of Natural Sciences, Massey University, Palmerston North, New Zealand. ${ }^{2}$ Centre for Brain Research, School of Biological Sciences, The University of Auckland, Auckland, New Zealand.

Received: 6 December 2021 Accepted: 23 January 2022

Published online: 09 February 2022

\section{References}

1. Hayashi K, Ogiyama Y, Yokomi K, Nakagawa T, Kaino T, Kawamukai M. Functional conservation of coenzyme Q biosynthetic genes among yeasts, plants, and humans. PLoS ONE. 2014;9(6): e99038.

2. Cullen JK, Abdul Murad N, Yeo A, McKenzie M, Ward M, Chong KL, et al. AarF Domain Containing Kinase 3 (ADCK3) mutant cells display signs of oxidative stress, defects in mitochondrial homeostasis and lysosomal accumulation. PLOS ONE. 2016:11(2): e0148213.

3. Reidenbach AG, Kemmerer ZA, Aydin D, Jochem A, McDevitt MT, Hutchins PD, et al. Conserved lipid and small-molecule modulation of COQ8 reveals regulation of the ancient kinase-like UbiB family. Cell Chem Biol. 2018:25(2):154-65 e11.

4. Stefely JA, Licitra F, Laredj L, Reidenbach AG, Kemmerer ZA, Grangeray $A$, et al. Cerebellar ataxia and coenzyme $Q$ deficiency through loss of unorthodox kinase activity. Mol Cell. 2016;63(4):608-20.
5. Traschutz A, Schirinzi T, Laugwitz L, Murray NH, Bingman CA, Reich S, et al. Clinico-genetic, imaging and molecular delineation of COQ8A-Ataxia: a multicenter study of 59 patients. Ann Neurol. 2020;88(2):251-63.

6. Gerards M, van den Bosch B, Calis C, Schoonderwoerd K, van Engelen $K$, Tijssen $\mathrm{M}$, et al. Nonsense mutations in CABC1/ADCK3 cause progressive cerebellar ataxia and atrophy. Mitochondrion. 2010;10(5):510-5.

7. Jacobsen JC, Whitford W, Swan B, Taylor J, Love DR, Hill R, et al. Compound heterozygous inheritance of mutations in coenzyme Q8A results in autosomal recessive cerebellar ataxia and coenzyme Q10 deficiency in a female sib-pair. JIMD Rep. 2018:42:31-6.

8. Lagier-Tourenne C, Tazir M, Lopez LC, Quinzii CM, Assoum M, Drouot $\mathrm{N}$, et al. ADCK3, an ancestral kinase, is mutated in a form of recessive ataxia associated with coenzyme Q10 deficiency. Am J Hum Genet. 2008;82(3):661-72.

9. Barca E, Musumeci O, Montagnese F, Marino S, Granata F, Nunnari D, et al. Cerebellar ataxia and severe muscle CoQ10 deficiency in a patient with a novel mutation in ADCK3. Clin Genet. 2016;90(2):156-60.

10. Blumkin L, Leshinsky-Silver E, Zerem A, Yosovich K, Lerman-Sagie T, Lev D. Heterozygous mutations in the ADCK3 gene in siblings with cerebellar atrophy and extreme phenotypic variability. JIMD Rep. 2014;12:103-7.

11. Cheng HL, Shao YR, Dong Y, Dong HL, Yang L, Ma Y, et al. Genetic spectrum and clinical features in a cohort of Chinese patients with autosomal recessive cerebellar ataxias. Transl Neurodegener. 2021;10(1):40.

12. Cotta A, Alston CL, Baptista-Junior S, Paim JF, Carvalho E, Navarro MM, et al. Early-onset coenzyme Q10 deficiency associated with ataxia and respiratory chain dysfunction due to novel pathogenic COQ8A variants, including a large intragenic deletion. JIMD Rep. 2020;54(1):45-53.

13. Hajjari M, Tahmasebi-Birgani M, Mohammadi-AsI J, Nasiri H, Kollaee A, Mahmoodi $\mathrm{M}$, et al. Exome sequencing found a novel homozygous deletion in ADCK3 gene involved in autosomal recessive spinocerebellar ataxia. Gene. 2019:708:10-3.

14. Hikmat O, Tzoulis C, Knappskog PM, Johansson S, Boman H, Sztromwasser $P$, et al. ADCK3 mutations with epilepsy, stroke-like episodes and ataxia: a POLG mimic? Eur J Neurol. 2016;23(7):1188-94.

15. Horvath R, Czermin B, Gulati S, Demuth $S$, Houge G, Pyle A, et al. Adultonset cerebellar ataxia due to mutations in CABC1/ADCK3. J Neurol Neurosurg Psychiatry. 2012;83(2):174-8.

\section{Publisher's Note}

Springer Nature remains neutral with regard to jurisdictional claims in published maps and institutional affiliations.

Ready to submit your research? Choose BMC and benefit from

- fast, convenient online submission

- thorough peer review by experienced researchers in your field

- rapid publication on acceptance

- support for research data, including large and complex data types

- gold Open Access which fosters wider collaboration and increased citations

- maximum visibility for your research: over $100 \mathrm{M}$ website views per year

At BMC, research is always in progress.

Learn more biomedcentral.com/submissions 